\title{
Robots and the Possibility of Humanistic Care
}

\author{
Simon Coghlan ${ }^{1}$ \\ Accepted: 15 June 2021 / Published online: 26 June 2021 \\ (c) The Author(s), under exclusive licence to Springer Nature B.V. 2021
}

\begin{abstract}
Care robots are likely to perform increasingly sophisticated caring activities that some will consider comforting and valuable. They will get increasingly humanlike and lifelike. This paper addresses the conceptual question: Even if robots can assist and ease people's suffering, can such machines provide humanistic care? Arguably, humanistic care is the most humanly distinctive and deepest form of care there is. As such, it may be thought to show most starkly the gulf between human and robot caregiving. The paper argues that humanistic caregiving is indeed a distinctive form of 'affective' care dependent on certain uniquely human characteristics or aspects of our humanity which can provide a profound kind of comfort to suffering people. It then argues that there is an important conceptual sense in which robots cannot provide humanistic care. Nonetheless, the paper subsequently suggests that we may recognize a useful sense in which robots, of a suitably anthropomorphic type, can provide humanistic care. Robots might 'express' to people with physical, social, or emotional needs the kind of humanistic care that only human beings can provide but that sufferers can nonetheless receive comfort from precisely because of what is expressed to them. Although this sense of humanistic robot care is derivative from uniquely human care, and although it is wide open to social and ethical criticism, it is nonetheless an idea worth clarifying for anyone interested in the possibilities and limits of robot care.
\end{abstract}

Keywords Care robots $\cdot$ Humanistic care $\cdot$ Aged care $\cdot$ Health care $\cdot$ Ethics $\cdot$ Anthropomorphism.

\section{Introduction}

Robots that provide care to people with physical, emotional, and social needs are likely to become increasingly popular as technology advances, populations age, and demand for human caregivers outstrips supply [1]. Robots will get increasingly sophisticated and lifelike. These prospects raise several related but different questions. One is the empirical question of the technological and practical possibilities of care robots and their effects on human beings, as investigated in fields like social robotics and human-robot interaction (HRI) [2-7]. Another concerns the social and ethical dangers and benefits of robots, particularly ones that increasingly

Submission for special edition: 'Beyond Anthropomorphism' (Guest editors: Chris Chesher, Naoko Abe and Raya Jones).

Simon Coghlan

simon.coghlan@unimelb.edu.au

1 Centre for AI and Digital Ethics (CAIDE), School of Computing and Information Systems, Faculty of Engineering and Information Technology, The University of Melbourne, Victoria 3010, Australia resemble humans, undertaking care work [8-18]. A third question concerns what sorts of care are conceptually possible for autonomous artificial agents that can act in increasingly lifelike and complex ways [19], compared to human actors [20].

This paper examines, by means of philosophical analysis, the third, conceptual question. It specifically investigates whether care robots can provide 'humanistic care' to people who are, for example, socially isolated, suffering physical or mental illness, or have various disabilities [21]. Some will think this prospect is obviously impossible, or possible only in a trivial sense, and perhaps also wrong or dangerous to attempt; others will pursue or embrace it with open arms. But if humanistic care, as some think, is a distinctively human form of care and is perhaps the deepest form of care that there can be, it may be thought to show most starkly the gulf between human and robot caregiving. Humanistic care may seem the polar opposite or perfect antithesis to robot care. Because humanistic care may be considered so peculiarly human and profound, focusing on it is a helpful litmus test of the limits and possibilities of robot caregiving, as robots get potentially more-and-more sophisticated 
and lifelike. It also feeds into discussions on how human or anthropomorphic care robots might need to be for various social purposes [22].

To get clearer about this conceptual territory, I elucidate below a vital sense of 'humanistic care' that has its home in uniquely human caregiving. I argue that humanistic caregiving is indeed a distinctive form of 'affective' care dependent on certain uniquely human characteristics and aspects of our humanity that can provide a profound kind of comfort to suffering people. Not all kinds of warm, emotion-laden, affective care need be humanistic care when the latter is understood in a certain way. I then try to elaborate a conception of robot humanistic care that is intelligible and substantial rather than misguided and unhelpful, and that will be useful for anyone interested in robot care.

The conception of humanistic robot care that I develop is conceptually derivative from distinctively human activity. It also implies that 'humanistic' care robots will need to be strongly anthropomorphic in physical and behavioral ways. Given the potential increase in sophisticated care robot use, this conception is important to clarify, even though (or indeed because) the design and use of 'humanistic care robots' is open to social and ethical criticism and may well be rejected by some care recipients, their caregivers, and others. Yet normative questions about new technology such as robots and AI sometimes benefit from clarification of underlying concepts [23]. For these reasons, this philosophical study of the nature of 'humanistic care', and of the associated potential and limits of robot caregiving, has implications for robot design, HRI, and the ethics of robot care.

The paper runs as follows. In Sect. 2, I provide some necessary background for our examination. In Sect. 3, I flesh out key conceptual constituents of humanistic caregiving performed by humans, drawing on the notion of a kind of humanism in caregiving propounded by individuals such as Oliver Sacks. In Sect. 4, I cast doubt on one skeptical view that humanistic human caregiving is not a special or unique kind of caregiving that can provide distinctive and profound forms of comfort to sufferers. In Sect. 5, I briefly present the different skeptical view that precisely because human caregiving is special and unique, therefore there can be no substantial conception whatever of humanistic caregiving by robots. I then elucidate, in line with my aim, what I think is a non-trivial and useful conception of such robot caregiving in Sect. 6. There I develop an 'expressivist' understanding of robot care in which robot humanistic care depends on care recipients having certain affective responses that depend conceptually on their responding to certain humanlike expressive features of the robots. In Sect. 7, I reply to some possible worries about this account. Finally, in Sect. 8, I briefly outline some implications of the preceding conceptual analysis for caregiving practice and research, robot interaction studies, robot design, and ethics.

\section{Background}

Care robots are a type of 'social robot' or 'socially assistive robot' $[24,25]$ which occupy social roles, inhabit social settings, and possess apparent social capacities or features [26]. Following Vallor, I define care robots roughly as "robots designed for use in home, hospital, or other settings to assist in, support, or provide care for sick, disabled, young, elderly, or otherwise vulnerable persons" [8]. They may assist health care professionals or work directly with care recipients, including by providing robot companionship as a form of care [13]. Care robots may be used in medicine and nursing, in rehabilitation, and in sectors such as aged care [27] for people who are frail, needing assistance, or lonely.

Unlike, say, avatars on video screens, care robots are embodied machines in the sense that they have physical form often in the shape of bodies. They may also have a kind of agency whereby they act of their own accord, i.e., to some degree autonomously. They may be human-like, animal-like, hybrids of the two, robot-like, and so on [28]. Some care robots may have AI-enabled abilities such as the ability to detect human emotions and perform natural language processing that allows them to hold conversations with people or enact other 'social' interactions [29]. While some people are hopeful that robots will become conscious and have emotions, thoughts, and phenomenal experiences in the way that biological creatures like humans and some animals do [30, 31], I shall assume that robots will not achieve consciousness, awareness, and so forth in the foreseeable future. This position is widely accepted. The care robots I have in mind thus have no 'interiority' even though they may have great sophistication, autonomous behavior, lifelikeness, and artificial intelligence.

There are many possible care robot activities [32]. We may, however, start by broadly distinguishing 'functional care' and 'affective care' [27, 33]. Functional care characteristically involves physical care tasks such as lifting, feeding, cleaning, bathing, diagnosing, taking temperatures, monitoring physiology and behavior, and reminding people to take medications. Affective care, by contrast, involves influencing a vulnerable or unwell person's affective state, such as their emotions. This care may be comprised of, for example, comforting, reassuring, and giving solace, or keeping company through illness, depression, and social isolation. Importantly, functional care and affective care can go together. We can witness this when, for example, a human nurse washes an anxious bedbound patient with gentle concern and reassurance.

Some examples of existing care robots will help to set the scene for our discussion. Consider functional care 
activities first. Robotic surgeons perform the functionalstyle care of repairing bodies [34]. Some robots assist in teleconsultations [35], including by (controversially) helping doctors deliver bad news [36], a prospect made more real by the COVID-19 pandemic when healthcare workers were in short supply [37]. RIBA is a large plastic-looking robot with a bear-like face and strong human-like arms for lifting and placing people onto beds and wheelchairs while being guided by "novel tactile guidance methods using high-accuracy tactile sensors" [38]. The fourth generation of the ambulatory Care-O-Bot has arms, neck, and hips that pivot on spherical joints and a 'head' with a screen interface. It can assist people by, for example, carrying objects for them [39].

Some care robots are designed to help functionally with social and cognitive function. ElliQ is a non-ambulatory home assistant robot for older people with a moveable 'head' that lights up during interaction and can converse with and pro-actively remind users go for a walk, talk to a friend or relative, or take medication [40]. Robots like Pepper and NAO (shiny robot-looking humanoids), Pleo (friendly-looking plastic dinosaur), and Kaspar (childlooking robot) have been used for younger people with Autism Spectrum Disorder, such as by providing them with non-threatening social therapy [41]. As can be seen, some care robots have clear anthropomorphic appearances and capabilities, while others do not.

Robots that provide functional care, such as ElliQ and even the vaguely anthropomorphic (human-like) Care-OBot, which is supposedly "courteous, friendly, and affable as a gentleman" [39], have some overlap with care robots that more explicitly aim at affective care. For example, robots are being designed that can hug people to alter affective states like moods and emotions in people in hospitals and aged care [42]. Block and Kuchenbecker explain:

Hugging another person gives each participant social support, relieves stress, lowers blood pressure, and increases oxytocin levels. With the health benefits and prevalence of hugs in daily human interactions, it is natural that roboticists have tried to artificially create this gesture [6] .

Certain 'companion robots', such as Paro the fluffy baby seal, give affective care by comforting and bringing enjoyment to older socially isolated individuals and those developing dementia [43, 44]. Paro has sensors that recognize voice and touch, such as stroking and patting, and can respond with apparent pleasure and affection to its user. Other companion robots, like Sony's robot dog AIBO, may become care robots that provide affective care when used in care settings, even though they are usually used at home as entertaining companions for people who don't need care
[45]. And again, affective and functional robot care may be wrapped into a single activity.

Discussions about robot care often touch on the idea of care that is not only affective but also peculiarly or strikingly human [17]. This might occur, for example, when people talk about care with heart or with the human touch that is allegedly present in the highest forms of care [46, 47]. Sometimes the tenor of such remarks is that there are special qualities that can make some kinds of human care [48] that express certain aspects of our humanity—or what I am terming 'humanistic care'-particularly distinctive, profound, and ethically fine [11,49]. Humanistic care may occur through the manner in which functional care is performed, or be independent of it. The suggestion that care robots might perform 'humanistic care' of some distinctive human sort can elicit at least three general responses that are worth classifying: embrace, rejection, and deflection. I will outline them here and return to both rejection and deflection later (finding both true aspects and weaknesses in them).

Embrace involves the view that humanistic care is a possible and even worthy aim of robot development. Note that there is a receptiveness to highly human-like robot care and companionship in some cultures [50], and some current trajectories are towards increasing anthropomorphization of robots [51]. For example, a recent HRI study suggested that robots designed to reduce loneliness may need to "manifest more positive unique human nature traits to facilitate people's anthropomorphism" and to "show more warmth" to promote "social connection with their human partners" [52].

Rejection, I will say, involves strongly criticizing the very idea that robots can provide humanistic care. Skeptics may, for example, say that humanistic care depends on robots having conscious or phenomenal experiences which they lack, or relatedly, on care recipients being deceived about the (absent) interiority of robots [49]. Rejection, I shall say, involves dismissing the idea that robots might be provide humanistic care in some intelligible sense.

Deflection involves the claims, made by some posthumanists [53], that we should be wary of valorizing "anthropocentric" styles of care [54] or of regarding them as particularly special, and that profound kinds of machine care can exist without needing the "quasi-mystical powers ascribed to the "human touch" [55]. On a certain posthumanist view, our attitude to robot care should aspire to get, as it were, 'beyond anthropomorphism'.

Making sense of the three general responses as I have described them requires at least a basic understanding of what humanistic care by humans and/or nonhumans is or could be. Although an investigation of humanistic robot care could be informed by studies about robots and human responses to them, my investigation here is primarily philosophical. Specifically, it proceeds by clarifying and investigating relevant concepts and the nature of various forms 
of caregiving, human behavior, and nonhuman action. Such an investigation is required to make sense of the possibility or the impossibility of humanistic robot care and what that notion might come to. For example, if humanistic care only really makes sense in relation to human caregivers, or if it necessarily depends on deception or delusion when undertaken by robots, then the project of trying to emulate particularly human-like forms of care in robots or of making caregiving robots increasingly 'in our image' may need reassessment. The following conceptual investigation could inform value sensitive robot design $[13,56]$, science and technology studies [57, 58], HRI studies [59-61], and the ethics of robot care $[10,17]$.

\section{Humanistic Care Performed by Humans}

To investigate the possibility of creating humanistic care robots, I begin by outlining some possible components of what we are calling humanistic care that occur in human caregiving. The concept of 'humanistic care', of care that expresses certain special aspects of our humanness or humanity, is too complex to elucidate exhaustively; it is also likely to be contested and debated. However, it is possible to delineate some of that concept's core features-or at least core features of a certain important conception of humanistic care-in a way that will be helpful to our conceptual investigation of the limits and possibilities of robot caregiving.

Humanistic care, of course, goes well beyond functional care. It may involve functional care, such as lifting or cleaning a patient, or improving their physical health or cognitive functioning, but it also involves affective care. Affective care, we noted, can occur independently of functional care or as a part of it. We may regard humanistic care as a kind of affective care. However, humanistic care is not just any kind of affective care, but a special form of it. Or at least, that is what many people believe, and it is also something we can give an account of. Before we delve into the idea of humanistic care, let us first discuss affective care more generally.

One component of affective care is an attempt to influence a person's affective state. For example, the caregiver might seek to reduce a person's loneliness or anxiety about their illness. Interest in patient-centered care and care for the whole person is increasing [62, 63]. Indeed, the World Health Organization's Practical Manual for using the International Classification of Functioning, Disability and Health emphasizes holistic care [21]. Patient-centered and holistic care go beyond promoting physical health to simultaneously or separately promoting emotional wellbeing. The philosophy of 'positive psychology' [64] is holistic insofar as it aims not only to relieve mental suffering and dysfunction but to foster emotional growth and flourishing.
Affective care can involve the expression of certain types of care, often affectively laden, on the part of the caregiver. Mark Coeckelbergh distinguishes 'shallow' care from 'deep' care [20]. On his definition, both forms can be 'good care' rather than 'bad care'. Yet shallow care for Coeckelbergh amounts to functional care, whereas deep care implies carerelated responses and engagement from, and/or the initiation of affective relations by, the caregiver. Such affective relations could include empathy and concern.

Santoni de Sio and van Wynsberghe distinguish "goaldirected" care activity in healthcare, where the good sought is external to the activity, and "practice-orientated" care activity, where the good sought is internal it [18]. Goaldirected care may for example involve lifting or moving a patient. Practice-oriented care is related to affective care; it may, for example, involve making eye contact and emotional connections with patients. We can note here that humanistic care is a kind of practice-oriented care. As such, the good of humanistic care is not reducible to external goals but is rather partly internal to such care. However, Santoni de Sio and van Wynsberghe suggest that although robots excel at goal-directed care, practice-oriented activities, in which the value of care is embodied in the activity itself, is a job for human beings rather than robots [18].

The philosophy of care [65-67] is also helpful. In care ethics, a distinction is often made between 'caring for', which need not involve conscious feelings and attitudes of care, and 'caring about', which necessarily does involve conscious feelings and attitudes [13, 68]. Care theorist Joan Tronto holds that (conscious) attentiveness, responsibility, and reciprocity are ineliminable parts of good care practice [68]. The finest caregiving means not simply, say, diagnosing an illness and dispensing medications; it also means having a complex and attentive relationship with the cared-for. Embedded in this nuanced relation is a range of possible affective responses like empathy, sympathy, concern, and compassion. Furthermore, care ethics stresses that this caring relationship is (ideally) penetrated by an ethical dimension, in which the caregiver recognizes responsibilities to the recipient and initiates actions to express that recognition and fulfil those responsibilities. In a similar vein, Rob Sparrow [11] argues that humans who are being cared for require both recognition as unique individuals and ethical respect as members of the human community [69].

The elements of seeking to have a positive effect on another who is ill or alienated (etc.) through the manifestation of ethically conditioned, affective, and expressive behaviors and actions are important to the idea of humanistic care. I need, however, to bring out a distinctive dimension of that concept that goes beyond just any kind of affective (e.g. empathetic) care. This dimension is related to certain distinctive human behaviors or aspects of our humanity. In a discussion of robots and nursing, Archibald and Barnard 
note that many health practitioners instinctively embrace "humanism" and see it as their role to sometimes "share their humanness with the patients they care for" [33]. What, we may ask, could this 'sharing of humanness' or humanity be? To get a sense of a core component of humanistic care that such expressions seem to hint at, I shall briefly turn to the thoughts of the well-known neurologist Oliver Sacks.

Sacks spoke of the humanistic clinician. He distinguished between viewing a patient as an organism needing repair on the one hand and seeing them, as it were, with fully human eyes on the other. Both stances, Sacks thought, are essential to full care on the clinician's part. Indeed, without a certain uniquely human component, the caregiver-who could be a doctor but also a nurse, an aged care worker, or even a person without any professional skills-is lacking a vital caregiving quality. Sacks held that:

...The humanistic clinician moves freely between the two narrative worlds of health care: the classical world, with its "objective description of disorders, mechanisms, syndromes," and the "romantic" world_-"an empathic entering into patients' experiences" of illness. [He/she] neither sees the patient "as an impersonal object nor as projections of himself," but rather as a fellow traveler through the course of the illness, all the while developing a perception of the patient "not as a problem [to be solved] but as a complex phenomenal whole...that requires imagination, empathy, and understanding" [70].

This form of humanistic care encompasses what we could call sympathetic understanding. The first word ('sympathy') can be read as shorthand for a range of key responses touched on above, like empathy, concern, compassion-and we could also add love [46] — that the caregiver might feel and express to the sufferer. The second word ('understanding') may be read as invoking Sack's particular contribution to our evolving concept of humanistic care. Understanding the sufferer could mean responses like registering them as a fellow traveler and mortal creature and so as fundamentally like oneself.

Of course, the affective dimension is certainly important: to have 'sympathetic understanding' is not merely to coldly or 'rationally' comprehend the other's state. But sympathetic understanding also means having and expressing a certain kind of knowledge and deep appreciation of the nature of their suffering, fears, alienation, and pain. It can mean, for example, registering and communicating, however subtly, human solidarity with them: the understanding that both the caregiver and the cared-for are vulnerable human creatures. Further, sympathetic understanding can involve expression of the loving sense that the recipient is profoundly valuable and unique. It is also worth noting that sympathetic understanding often - though, because of the power of the human imagination, not always-depends on actual human experience. This is why cancer sufferers, for example, often seek out the company of fellow cancer sufferers and why the bereaved seek the company of those who have recently suffered the loss of a loved one.

So, our conception of humanistic caregiving is care that can have certain effects on the recipient, such as comfort, reassurance, solace etc., which are produced in virtue of the care recipient recognizing that the caregiver is expressing key aspects of their own (the caregiver's) humanness or humanity. As we have noted, humanistic caring can involve such things as compassionate solidarity, fellow feeling, and the view that the recipient is profoundly valuable and unique. This might be called affective care, but it is affective care of a particular sort that draws on fundamental and profound dimensions of human life.

Several qualifying remarks about this idea of humanistic care must be made. First, there is no 'official' concept of humanistic care, the concept is anyway complex, and people are free to define it differently. Even so, the descriptions I have presented are I think recognizable as elements that many care scholars and others implicitly resonate with when they talk of distinctively or uniquely human care. Some instances of humanistic caregiving may involve sympathetic understanding, while other instances may tend to stress the uniqueness of the care recipient, and so on. But what qualifies caregiving as humanistic is that at least some of these key and distinctive elements of 'humanness' are present.

Second, we can acknowledge that human caregivers may often fail to care well, and especially to care humanistically, since caring can, for various reasons, be hard and unrewarding work [54]. In reality, caregivers may lack genuine opportunities to really 'share their humanness' as opposed to just 'going through the motions'. Humanistic care may be all too rare, which helps explain why people like Oliver Sacks so strongly champion it. Nonetheless, humanistic care is a kind of care that many people strongly believe is worth aspiring to and, of course, worth receiving.

Third, humanistic care can be expressed in many different bodily ways. For example, it can be conveyed in words or else simply in a gesture, a non-linguistic utterance, a demeanor, or a look, action, or touch. Indeed, that human caregivers express humanistic forms of care in various ways and by means of their bodies is a fact of great significance. Sometimes this care might be expressed by way of the words which are said and by the speaker's tone of voice. Tactile interactions are also often central. Embracing a patient or holding their hand, activities which manifest the "power of touch," [33] can be ways of expressing, say, sympathetic understanding, even when that understanding is not conveyed by linguistic means (although it might be).

Even just being with a suffering person at a key moment and showing them a human face can in the right contexts 
be a significant form of caring that expresses sympathetic understanding [71]. So too can be simple acts of kindness, such as noticing that a person is sad or lonely and offering them a kind word, a reassuring touch, or cup of tea. All these could be examples of what some have called "humanistic nursing" [72]. In sum, behaviors like compassion and kindness, when expressed in certain bodily ways by human beings such that they express certain peculiarly human responses like sympathetic understanding and solidarity, can constitute humanistic care for the care recipient. Having given some sense of this distinctive variety of human care, let us now consider two skeptical responses-deflection and then rejection-to the idea of robots performing humanistic care. I will suggest that both responses have some value, but that they also have weaknesses.

\section{Deflection of Robot Humanistic Care}

Deflection involves the belief that the project of trying to make care robots increasingly in the human image is problematic because it involves an overinflated view of human beings and a narrow view of the possibilities of nonhuman styles of caregiving. Such a belief might be gleaned from posthumanism's $[53,73]$ radical critique of a kind of liberal humanism or anthropocentrism that many cultures have inherited. While this stance need not dismiss human caregiving altogether, it does seek to unsettle traditional ideas of caregiving by shaking human beings off their pedestal.

For example, those who critique a traditional and essentially human-centered conception of care may point to the possibility and great value of non-human and non-anthropomorphic — but still embodied-types of care. They may, for instance, welcome human-nonhuman hybrid models of care that undermine hard but often unexamined boundaries between machines, humans, and animals [74]. On this view, we should be open to reconceiving robots not as cold, mechanical objects as we have often learnt to do, but as nonhuman agents that, in spite of looking like machines or machine-creature hybrids, may offer novel, rich, and intrinsically rewarding caring entanglements for the dependent and vulnerable human creatures that we are [75]. Some critics may even question whether commentators like Mark Coekelbergh are right to claim that "good care" necessarily involves "a significant amount of human contact" [19].

Posthumanist critic Amelia DeFalco argues that we must "move beyond the assumption that human care is the gold standard" [55]. She writes:

Companion robots like Paro appeal to the desire for affective reciprocity, fabricating a relationship in which users are able to simultaneously receive and give care. Robots, such as Paro, usurp what many assume are exclusively human prerogatives of caregiving-affection, intimacy, even love-destabilizing humanistic models of care that privilege human-to-human relations as uniquely authentic and meaningful [54].

I am unsure what precisely DeFalco would make of the idea of rendering care robots ever more like human beings as opposed to exploring less human or less anthropomorphic modes of robot care. Nonetheless, the posthumanist deflation of the humanistic care position as I have explained it provides an argument against thinking that humanistic care robots are worth pursuing on account of the unique and profound value of humanistic care. The posthumanist deflection-as I am taking it here-of the idea that we might humanize care robots by modelling them ever more closely on human beings stems from a deep critique of anthropocentrism. There are, however, arguably good reasons for holding that humanistic care, as it is esteemed by humanistic thinkers like Oliver Sacks and others, is distinctive and special, even as we remain open to novel and radically nonhuman forms of caregiving.

Consider nonhuman animal care. Animal-assisted therapy is flourishing [76, 77]. This emerging field of healthcare recognizes not only the enormously comforting and healing power of animal interaction and company, but also the affective responses and the skills that highly experienced and trained animals such as dogs may bring to caregiving. Some scholars of animal-assisted therapy do not regard such animals as mere 'therapeutic tools' for human therapists to use and manipulate, but as engaged nonhuman co-therapists who work in co-operation with (albeit under the guidance of) professional human therapists [77].

The idea of animals as sophisticated and genuine co-caregivers or even co-therapists is, while a challenging idea for some, a possibility that we might be receptive to. But even such advanced animal caregiving will never be humanistic care. Animals can arguably show empathy, sympathy, and skilled responses which we may sometimes recognize as invaluable caregiving, but they cannot, for example, embrace, hold hands, or sit with a person and console them in the same way a human caregiver can. Embodied animal expressions of care may convey understanding from those animals - and the erosion of skepticism about animal minds should awaken us to their complexity — but animals nevertheless do not and cannot communicate such things as a sympathetic understanding of a sufferer as a uniquely valuable fellow traveler. Therefore, robot animals similar to, or even much more advanced than Paro, cannot provide humanistic care, even if people affectively bond with them and even if they express kinds of 'affect' which in turn positively influence the emotions and mood of human recipients, as some studies indicate they do [78]. 
Of course, posthumanist critics may reply that these points about animal care exemplify the anthropocentric bias we have reason to escape. However, it seems that human sufferers often still strongly want and need distinctively human care. In a recent scoping review of human compassion in the healthcare literature, Sinclair et al. report that patients and their families "consistently ranked features of [human] compassion among their greatest healthcare needs" [79]. And while it is evident that patients "desperately desire and increasingly expect compassion to be a core component of their healthcare experience", these needs are, unfortunately, frequently unmet by professional caregivers [79]. A critic may cogently reply that compassion could also come, and perhaps come more consistently and reliably, from animals or indeed (in a different sense) from robots. However, reflection on other examples may convince us that we have not yet landed in a posthumanist world in which humanistic compassion is no longer often central to the vital care needs that lonely, sick, disabled, or depressed human beings have and profess.

During the COVID-19 pandemic, restrictions on human contact and overrun medical services meant that some victims suffered and died alone. Medical staff were forced to wear heavy personal protective equipment (PPE) that placed physical barriers between them and their patients. Something similar happened during the earlier Ebola epidemic. In the following extract, a nurse describes her experiences tending to patients dying from Ebola virus:

Having to wear full person protective equipment (PPE) affected nursing tasks. (I sometimes felt as if I were trapped inside the body of a robot.) Patients couldn't see the faces of those caring for them, and this was particularly distressing for children, many of whom were in the isolation area alone because their family members either had died or weren't infected. Patients could be touched only with gloved hands, and this profoundly limited nurses' ability to establish human connections [80].

Our discussion of humanistic care has already identified some key elements of such 'human connections' that are, as this nurse and author says, communicated by human faces and hands and that were so important to her patients. Although I agree with those who stress that we should be open to other forms of care (such as animal caregiving), I also believe that humanistic care is a unique and profound sort of care which only living human beings, with their human experiences, frailties and vulnerabilities, and forms of understanding, can fully provide. However, I also want to claim that complete rejection of the possibility of humanistic robot caregiving is mistaken. And yet the preceding quote from the Ebola nurse, in which 'faceless' human beings in heavy PPE are described as looking like robots, may be thought to suggest that care robots, no matter how sophisticated and cleverly designed, are the perfect antithesis of humanistic caregivers.

\section{Rejection of Robot Humanistic Care}

Various authors have strongly critiqued the project of designing and deploying robots for certain caregiving purposes [46, 49, 81]. Care robot critics are usually not against machine-facilitated care altogether. They may acknowledge that care robots are efficient, untiring, relatively unobtrusive compared to humans, never abusive or insolent, potentially less invasive of privacy [81], and helpful to overworked caregivers [82]. Furthermore, some authors think that care robots might usefully assist in the provision of embodied and affective connections delivered by living human beings to those in need-such as by better enabling human caregivers to reassuringly touch and make eye contact with care recipients while lifting and carrying them [13].

Nonetheless, there is a concern that care robots might damage care practices that are necessary for the wellbeing of both care receivers and potential caregivers $[8,46]$. Rob Sparrow claims that "robots cannot provide genuine care because they cannot experience the emotions that are integral to the provision of such care" [11]. Robots also lack frailties such as mortality and vulnerability to disease, and the experience of hardship, which both humans and animals may possess [49]. Sparrow's story of an aged care home staffed entirely by caregiving robots [11] is intended to elicit our concern partly because human caregivers are absent (and the residents don't seem to mind it) and partly because, Sparrow thinks, robot care that aims to emulate human care must either fail or necessarily be deceptive [83].

Jennifer Parks crystallizes such feeling about care robots when she worries that their use:

Underestimates the deep human need to relate in an authentic and genuine way to another flesh-and-blood human being who appreciates one's uniqueness. Even the most finely tuned and responsive robot cannot provide the kind of authentic, honest, and human relationship upon which elderly citizens thrive...[people] may yearn for a pat on the hand, a back or foot rub, or an embrace. This yearning arguably cannot be fulfilled by a robot, since the very need to be considered unique and special by another cannot be met-except through deception—by a machine [46].

We would misunderstand Parks' claim if we took her to be saying that that robots will never meet the technical requirements of providing such 'authentic care' or that people will not find them comforting. Parks' objection is rather that robots, short of becoming "flesh-and-blood" beings like 
humans, cannot provide truly human kinds of care in principle, that is, for conceptual reasons. Although there is an important truth in that thought, I now want to explore why we might leave room for the idea of humanistic care from robots.

\section{Robot Humanistic Care}

In the light of the forgoing clarifications, it may appear that there is little room left for a useful notion of robot humanistic care. After all, I have accepted that there is a unique, profound, and vital kind of caregiving that is humanistic and which only humans and not robots, nor even skilled, flesh-and-blood animal caregivers, can provide. However, I still think there is a notion of robot humanistic care that is worth explicating. To explicate it, I shall employ a kind of 'expressivist' understanding of robots in which their autonomous behavior can be understood as embodying the behavior of feeling and thinking creatures [cf. 84, 85]. An expressivist understanding of robot humanistic care is conceptually parasitic on the humanistic caregiving behavior of humans and is importantly different from it. Nonetheless, it is an understanding that could go with an acceptance or a qualified acceptance (rather than a rejection of deflection) of humanistic robot caregiving - although there will still be room to ethically and socially critique it.

To be clear, there is a crucial sense in which it is true that robots, lacking human interiority and other human qualities and vulnerabilities, can only mimic or simulate genuine or authentic humanistic care [32]. Nevertheless, this does not rule out a non-trivial and useful sense in which robots could provide humanistic care in some potentially compelling way. Arguing that robots can provide more than cold, instrumental care such as taking blood pressure, Pols and Moser [86] note that a robot can cheer a lonely or depressed person by making them laugh and lifting their spirits. The dejected patient may have significant affective responses to the care robot such as affection, pleasure, companionship, and joyresponses that also benefit them emotionally.

We should, however, remember that humanistic care is not reducible to the causation of such effects, even though those effects are an important part of humanistic care and even though we may want to call that sort of care 'warm' rather than 'cold' care. Another important component of humanistic care is that the caregiver behaves in some of the expressive kinds of ways that we discussed earlier. To explain this component further, let us imagine a robot that, partly by reading postures of human bodies or expressions on human faces (as a robot like Pepper does in a rudimentary way [87]), can identify when a person is feeling especially down and can then gently touch their shoulder or give them a hug. Perhaps the robot does this for a socially isolated person, or perhaps someone suffering from severe COVID19 or Ebola, where human caregivers are too exhausted or too encumbered by heavy PPE to touch or hug dying patients.

Imagine that this robot touches a person's hand or shoulder or embraces them with strikingly anthropomorphic arms, hands, face, and body, and in a manner is evocatively human. Block and Kuchenbecker recently investigated both the mechanics of and participant responses to a simple hugging robot [6]. They explored certain variables like the softness of the robot's arms and body and the firmness of the hug. Their robot, though still fairly rudimentary, can detect, for example, when the person is beginning to release from the hug and react as a human would. Participants in this study preferred soft, warm hugs that "physically squeeze them and release immediately when they are ready for the hug to end" [6].

Compared to a lifting or feeding robot, the hugging robot may initially seem to have little functional benefit in a caring context. However, human beings tend to find physical contact such as embraces from other human beings relaxing and comforting. A robot that replicates the right tactile feel of human skin and exercises just the right amount of pressure and timing in performing a human-style embrace might, for example, reassure and comfort a sick person and even lift their spirits $[9,10]$.

However, we cannot call this activity robot humanistic care despite those outcomes for the cared-for. For one thing, a comforting effect might be achieved by, for example, giving a person tight-fitting clothing that replicates the feel of a hug, or, more technologically, the smartphone-linked Tjacket-a device its manufacturer claims "provides customizable deep touch pressure hugs that help calm and comfort people who are anxious or stressed" [88]. Furthermore, even if this imagined robot behaves in affective ways, such as 'showing' empathy, such expressive affective care is not necessarily humanistic robot care. To get to humanistic care, we need to imagine an 'android' that has a certain anthropomorphic appearance and that touches or hugs the sufferers in humanlike ways that express, say, sympathetic understanding and solidarity. Certain words or utterances, and the manner in which they are made, may also be part of the android's humanistic expression.

For reasons explained, touching, being hugged, etc. by an android necessarily (conceptually) cannot replace a genuinely human touch or embrace, even if the android and its behavior are strikingly humanlike. Furthermore, what the suffering person most wants, and needs, may be comforting physical contact from a living, flesh and blood human being. Nonetheless, the sufferer may be comforted and consoled by our imagined android precisely because of the distinctively human care that its body, voice, and behavior expresses to them. Importantly, this sufferer feels consoled in virtue of 
the fact that the robot performs an action that, due to its expressive, embodied qualities, strongly evokes the humanistic caring actions of a human being.

In contrast, the person comforted by, say, a Tjacket, an animal robot, or even many 'affective' anthropomorphic robots does not feel comforted in virtue of receiving a human-like hug that compellingly evokes humanistic qualities. The manner or form of a person's comfort, should they receive it, is importantly different for these other devices. The touch, words, or embrace will not count as humanistic robot care if it merely induces certain beneficial physical effects, for that is merely functional care. But nor will it count as humanistic care if it is 'merely' a sort of affective care that, while expressing caring qualities and inducing corresponding emotional effects, lacks the requisite expressive humanistic elements. The care recipient must regard the robot as expressing a human kind of response with some of the important qualities like sympathetic understanding and human solidarity which we described earlier.

A requirement for there being any substantial sense of robot humanistic care is, I want to suggest, that it must make a certain kind of sense for the care receiver to regard the robot's behaviour as expressive of human compassion, understanding, solidarity, etc. This introduces an intersubjective or 'objective' conceptual requirement. After all, a person might vividly (and perhaps non-deludedly) imagine that a hospital pillow that they hugged had expressed for them a humanistic embrace. However, pillows surely cannot express humanistic qualities in any sense that is useful for a conception of nonhuman humanistic caregiving. That is so even if the nature of artefacts is, as social constructivist accounts claim, partly conditioned by their cultural milieu of use [89]— such as the "meaning-infused" context of healthcare [84]. The context of the robot behavior may indeed inform the nature of its expressiveness, but that expressiveness still needs to have other elements to count as humanistic.

So, interpreting care robot behavior in humanistic terms, in a way that is helpful for those of us with various disciplinary or non-disciplinary interests in healthcare technology, depends on various features (including the context of use) and, I now need to say, on the way a sufficient number people respond to it. Classic studies have revealed remarkable human predispositions toward attributing human characteristics to digital technologies, even ones that do not or only vaguely resemble humans, such as computer programs [90]. Nonetheless, there are, as we have just noted, limits to the objects and behaviors that can be helpfully said to express comforting and consoling care of a humanistic kind.

Of course, presumably some robots and behaviors have the ability to express such care more powerfully and vividly than others, giving them the potential to be more effective in caregiving contexts. And we can imagine a range of robot possibilities that might, given technological advances, the right robot appearance, robot behavior, and the presence of appropriate contexts, compellingly express humanistic care. Examples could include forms of tender touching and responsiveness to being touched [91], AI-enabled learning about specific patients and their individuality, reassuring conversation [92], and telling a story [93] to a depressed or distressed person. A robot might even portray such human vulnerability as can intimate human fellowship. Whether such actions warrant the description 'humanistic robot care' depends on many (possibly subtle) details, and, furthermore, on how people respond to them.

\section{Conceptual Concerns About the 'Expressivist' Robot Account}

I shall now consider some possible conceptual concerns about our expressivist account of robot humanistic care. Rob Sparrow suggests [83] that if care recipients are intelligibly to benefit from sympathetic robot care, then they necessarily must be deceived that the robots are actually performing the relevant affective behaviors rather than merely simulating them. On this view, were people not at some level so deceived, it would be difficult to imagine how they could possibly feel comforted by an expression of (say) sympathetic solidarity from a mere machine. And if, instead, they are deceived, then the solace and comfort which they take from the robot is, regrettably (and possibly unethically), a false solace and comfort generated by the mere illusion of humanistic care.

However, on our 'expressivist' understanding, the care recipient is not comforted (etc.) by an illusory a delusory impression of humanistic care, but simply by the vivid appearance [94] and expression of a humanistic kind of care that the recipient knows emerges from human life and peculiar human behaviors. It is true that many people might not in the slightest be comforted by humanistic robots; others may recoil when they appear too uncannily human [24, 95]; still others may be comforted only in extremely isolated and desperate circumstances, such as in the Ebola and COVID-19 crises. The acceptance of such robots may also be affected by a patient's age, personality, gender, culture, or experience with technology [96-99]. In any case, those not consoled by humanistic care robots clearly cannot benefit from them.

Nevertheless, someone who is so comforted need not be deceived (even if some are) when they are moved by robot caregivers that express themselves humanly. And perhaps it should not surprise us that some people, especially those wracked by suffering and loneliness, should find a robot's facial expression, or the very human sound of its voice, comforting and reassuring. After all, we can be comforted and 
uplifted by many things in nature, not only by animals, but also inanimate things - the sound of a stream bubbling over stones or a breeze gently rustling through leaves. Certainly, the difference in our case is that we are speaking of robots acting in peculiarly human ways. Yet the power of nonhuman comfort is worth remembering. We know that empirical studies show people often accepting and even warming to social robots [100-102]. Similar studies would be required to know what individuals and groups think about humanistic robot care.

Another possible concern about our 'expressivist' account is that while we have pointed to the need for the right sort of appearance, context, and behavior, we have not given definite or exhaustive conceptual criteria for the expression of robot humanistic care. Why might some robots, but not other 'affective' care robots, be said to express humanistic care? In reply, we may point out that the expressivist notion is connected to the idea of what a thing intelligibly "represents," [19]. As Sparrow puts it in his illuminating discussion of a very different class of personal robots, it is connected to what we register as the meaning or "semantic content" [103] of robot behavior in human-robot interaction.

As was suggested above, the meaning or semantic content of robot behavior is not fixed subjectively by a single person and her imagination but is rather determined intersubjectively or 'objectively'. Accordingly, we can ask what meaning we can make of this or that robot and its behavior. Indeed, we may think that a person who fails to register the expression of a kind of humanistic care in a certain robotpicture again an advanced robot with human hands, arms, body, and face that detects human suffering and loneliness and responds with apparent bodily tenderness and wellchosen words of solace and comfort-is not so much seeing reality clearly as they are missing something. We cannot interpret any behavior as humanistic care, but sometimes (we can at least imagine) it will be hard or impossible to resist such an interpretation.

\section{Some Implications for Robot Research and Ethics}

One feature distinguishing virtual depictions of caring behavior (such as through an screen-based avatar) and robot behavior is that robots have bodies that can take on various physical forms and can autonomously interact with us. It is in this autonomous, embodied way that they might express a humanistic caring that, though certainly not equivalent to human sympathetic understanding, may still be compelling. The humanistic power of these interactions might increase not by moving care robots, as some would prefer, 'beyond anthropomorphism', but rather by giving robots more human appearances. Hands, faces, postures, gestures, demeanors, haptics, tactility, responsiveness, conversation-robots may better express humanistic care when these are more vividly humanlike [104-106] rather than, say, cartoonish, robotlike, or zoomorphic. No doubt increasingly humanlike robots run risks of seeming creepy or (just as terminally) simply laughable. Yet some such likeness is necessary to produce the relevant expressive qualities.

Healthcare research tells us that subtle body language and eye contact [107], tone of voice [108], and even supplementary humor [79] are important in establishing warmly compassionate connections between caregivers and recipients. Deeper knowledge of peculiar humanistic possibilities for robots will also depend on empirical studies in robot technology and HRI. For instance, investigations into soft robots [109], emotional recognition [110], recognition of specific human individuals, personalization, pro-activity, fluent humanlike conversation and bodily interaction [69]—and their various effects on vulnerable humans-should increase understanding of robots' potential for nonhuman humanistic caregiving.

Understanding of these possibilities may also increase when robot researchers collaborate with social scientists, artists, dramatists, cultural critics, and philosophers. Chesher and Andreallo illustrate this potential when they discuss the interplay of science, art, and philosophy in informing understanding of the meaningful and affective qualities of robot faces [111]. Novelists, poets, and others may also provide insight into the emotive power of certain linguistic formulations and utterances. Of course, to qualify as humanistic care robots, the idea of the distinctively human forms of care that we explored earlier needs to be kept in mind in conducting these empirical and non-scientific investigations.

None of what I have said implies that humanistic robot care, even if it were to be well-received by some patients, would be as or more important than functional care or indeed other kinds of affective robot care. Moreover, the worth of developing humanistic care robots depends significantly on our social and ethical appraisal of that endeavor. The suggestion that care robots need to be highly anthropomorphic [22] in order to compellingly express humanistic care could be used to argue either for or against such robot development. Thus, some critics may argue that this development will reinforce a dangerous slide toward replacing human caregiving with robot care; others will contend that the very idea is morally undignified and repellent [17]. In contrast, supporters may argue that the dangers of 'dehumanized' caregiving [112] are overstated, that humanistic robot care could assist the vulnerable, and that such robots may be a valuable addition to an increasingly overwhelmed care workforce. But my aim in this essay was conceptual understanding-social and ethical criticism of humanistic robot care must be treated separately. 


\section{Conclusion}

In this conceptual investigation, I argued that care robots might provide humanistic care in a sense that is useful to understanding the possibilities of robot caregiving. This sense, to be sure, is a limited sense, one that is derivative from humanistic care that originates in human caregiving and that involves genuine sympathetic understanding, human solidarity, and so on. I focused on the conceptual task of elucidating the meaning of robot humanistic care using an 'expressivist' approach. Further research would be required to determine just how effective humanistic robot care can be at consoling and comforting sufferers and to ascertain which robot designs are the most compelling. The paper's contribution lies in clarifying how humanistic robot care is intelligible (without requiring care receivers to be deceived or deluded) and in expounding what humanistic care consists in. We saw how humanistic care differs from functional care and, more importantly, from non-humanistic affective care. Given our understanding of the possibilities and limits of humanistic robot caregiving, we could go on to ask the social and ethical question of whether developing humanistic care robots is a good or a bad thing.

Acknowledgements I would like to thank the anonymous referees for their very helpful comments.

\section{Declarations}

Conflicts of interest The author declares no conflicts of interest.

\section{References}

1. Poulsen A, Burmeister OK (2019) Overcoming carer shortages with care robots: dynamic value trade-offs in run-time. Australas J Inf Syst. https://doi.org/10.3127/ajis.v23i0.1688

2. Frennert S, Aminoff H, Östlund B (2020) Technological frames and care robots in eldercare. Int J of Soc Robotics. https://doi. org/10.1007/s12369-020-00641-0

3. Johansson-Pajala R-M, Thommes K, Hoppe JA et al (2020) Care robot orientation: What, Who and How? Potential Users' Perceptions Int J Soc Robotics. https://doi.org/10.1007/ s12369-020-00619-y

4. Willemse CJAM, van Erp JBF (2019) Social touch in humanrobot interaction: robot-initiated touches can induce positive responses without extensive prior bonding. Int J of Soc Robotics 11:285-304. https://doi.org/10.1007/s12369-018-0500-9

5. Chen TL, King C-HA, Thomaz AL, Kemp CC (2014) An Investigation of Responses to Robot-Initiated Touch in a Nursing Context. Int J of Soc Robotics 6:141-161. https://doi.org/10.1007/ s12369-013-0215-X

6. Block AE, Kuchenbecker KJ (2019) Softness, warmth, and responsiveness improve robot hugs. Int J of Soc Robotics 11:49_ 64. https://doi.org/10.1007/s12369-018-0495-2

7. Chita-Tegmark M, Scheutz M (2020) Assistive robots for the social management of health: a framework for robot design and human-robot interaction research. Int J of Soc Robotics. https:// doi.org/10.1007/s12369-020-00634-z

8. Vallor S (2011) Carebots and caregivers: sustaining the ethical ideal of care in the twenty-first century. Philos Technol 24:251. https://doi.org/10.1007/s13347-011-0015-x

9. Borenstein J, Pearson Y (2012) Chapter 16: Robot Caregivers: Ethical Issues across the Human Lifespan. In: Lin P, Abney K, Bekey G (eds) Robot ethics: the ethical and social implications of robotics. MIT Press, Cambridge, MA, pp 251-265

10. Sharkey N, Sharkey A (2012) Chapter 17: The rights and wrongs of robot care. In: Lin P, Abney K, Bekey G (eds) Robot ethics: the ethical and social implications of robotics. MIT Press, Cambridge, MA, pp 267-282

11. Sparrow R (2016) Robots in aged care: a dystopian future? AI \& Soc 31:445-454. https://doi.org/10.1007/s00146-015-0625-4

12. Borenstein J, Pearson Y (2010) Robot caregivers: harbingers of expanded freedom for all? Ethics Inf Technol 12:277-288. https://doi.org/10.1007/s10676-010-9236-4

13. van Wynsberghe A (2013) Designing Robots for Care: care centered value-sensitive design. Sci Eng Ethics 19:407-433. https:// doi.org/10.1007/s11948-011-9343-6

14. Draper H, Sorell T, Bedaf S et al (2014) Ethical dimensions of human-robot interactions in the care of older people: insights from 21 focus groups convened in the UK, France and the Netherlands. In: Beetz M, Johnston B, Williams M-A (eds) Social Robotics. Springer International Publishing, Cham, pp 135-145

15. Draper H, Sorell T (2017) Ethical values and social care robots for older people: an international qualitative study. Ethics Inf Technol 19:49-68. https://doi.org/10.1007/s10676-016-9413-1

16. Stahl BC, Coeckelbergh M (2016) Ethics of healthcare robotics: Towards responsible research and innovation. Robot Auton Syst 86:152-161. https://doi.org/10.1016/j.robot.2016.08.018

17. Vandemeulebroucke T, Dierckx de Casterlé B, Gastmans C (2018) The use of care robots in aged care: a systematic review of argument-based ethics literature. Arch Gerontol Geriatr 74:1525. https://doi.org/10.1016/j.archger.2017.08.014

18. Santoni de Sio F, van Wynsberghe A (2016) When Should We Use Care Robots? The nature-of-activities approach. Sci Eng Ethics 22:1745-1760. https://doi.org/10.1007/s11948-015-9715-4

19. Coeckelbergh M (2015) Artificial agents, good care, and modernity. Theor Med Bioeth 36:265-277. https://doi.org/10.1007/ s11017-015-9331-y

20. Coeckelbergh M (2010) Health care, capabilities, and AI assistive technologies. Ethic Theory Moral Prac 13:181-190. https://doi. org/10.1007/s10677-009-9186-2

21. WHO (2001) International Classification of Functioning, Disability and Health (ICF). https://www.who.int/standards/class ifications/international-classification-of-functioning-disabilityand-health. Accessed 1 Feb 2021

22. Jecker NS (2020) You've got a friend in me: sociable robots for older adults in an age of global pandemics. Ethics Inf Technol. https://doi.org/10.1007/s10676-020-09546-y

23. Salles A, Evers K, Farisco M (2020) Anthropomorphism in AI. AJOB Neurosci 11:88-95. https://doi.org/10.1080/21507740. 2020.1740350

24. Pino M, Boulay M, Jouen F, Rigaud AS (2015) "Are we ready for robots that care for us?" Attitudes and opinions of older adults toward socially assistive robots. Front Aging Neurosci. https:// doi.org/10.3389/fnagi.2015.00141

25. Dautenhahn K (2007) Socially intelligent robots: dimensions of human-robot interaction. Philos Trans R Soc B Biol Sci 362:679-704. https://doi.org/10.1098/rstb.2006.2004

26. Sheridan TB (2020) A review of recent research in social robotics. Curr Opin Psychol 36:7-12. https://doi.org/10.1016/j.copsyc. 2020.01 .003 
27. Broekens J, Heerink M, Rosendal H (2009) Assistive social robots in elderly care: a review. Gerontechnology 8:94-103. https://doi.org/10.4017/gt.2009.08.02.002.00

28. Coghlan S, Waycott J, Neves BB, Vetere F (2018) Using robot pets instead of companion animals for older people: a case of'reinventing the wheel'? In: Proceedings of the 30th Australian Conference on Computer-Human Interaction. pp 172-183

29. Ng HG, Anton P, Brügger M, et al (2017) Hey robot, why don't you talk to me? In: 2017 26th IEEE International Symposium on Robot and Human Interactive Communication (RO-MAN). pp 728-731

30. Metzler TA, Lewis LM, Pope LC (2016) Could robots become authentic companions in nursing care? Nurs Philos 17:36-48. https://doi.org/10.1111/nup.12101

31. Danaher J (2020) Welcoming robots into the moral circle: a defence of ethical behaviourism. Sci Eng Ethics 26:2023-2049. https://doi.org/10.1007/s11948-019-00119-x

32. Turkle S (2006) A nascent robotics culture: New complicities for companionship. American Association for Artificial Intelligence (AAAI), Palo Alto, CA

33. Archibald MM, Barnard A (2018) Futurism in nursing: technology, robotics and the fundamentals of care. J Clin Nurs 27:24732480. https://doi.org/10.1111/jocn.14081

34. Van Wynsberghe A, Gastmans C (2008) Telesurgery: an ethical appraisal. J Med Ethics 34:e22-e22. https://doi.org/10.1136/jme. 2007.023952

35. Iannuzzi D, Grant A, Corriveau H et al (2016) Specification of an integrated information architecture for a mobile teleoperated robot for home telecare. Inform Health Soc Care 41:350-361. https://doi.org/10.3109/17538157.2015.1033527

36. Caplan A (2019) Doctors Must Give Life-or-Death News in Person, Not by Telemedicine. In: Medscape. http://www.medscape. com/viewarticle/910938. Accessed 26 Jan 2021

37. Wolf I, Waissengrin B, Pelles S (2020) Breaking bad news via telemedicine: a new challenge at times of an epidemic. Oncologist 25:e879-e880. https://doi.org/10.1634/theoncologist. 2020-0284

38. RIKEN-TRI (2020) RIBA Official Page RIKEN-TRI Collaboration Center for Human-Interactive Robot Research (RTC). http:// rtc.nagoya.riken.jp/RIBA/index-e.html. Accessed 26 Jan 2021

39. Fraunhofer (2015) Care-O-bot 4. In: Fraunhofer Institute for Manufacturing Engineering and Automation. https://www.careo-bot.de/en/care-o-bot-4.html. Accessed 26 Jan 2021

40. Intuition Robotics (2020) ElliQ, the sidekick for happier aging. In: Intuition Robotics. https://elliq.com/. Accessed 26 May 2020

41. Ramírez-Duque AA, Aycardi LF, Villa A et al (2020) Collaborative and inclusive process with the autism community: a case study in Colombia about social robot design. Int J Soc Robot. https://doi.org/10.1007/s12369-020-00627-y

42. Shiomi M, Nakata A, Kanbara M, Hagita N (2020) Robot reciprocation of hugs increases both interacting times and self-disclosures. Int J Soc Robotics. https://doi.org/10.1007/ s12369-020-00644-x

43. Moyle W, Cooke M, Beattie E et al (2013) Exploring the effect of companion robots on emotional expression in older adults with dementia: a pilot randomized controlled trial. J Gerontol Nurs 39:46-53. https://doi.org/10.3928/00989134-20130313-03

44. Wada K, Shibata T (2006) Robot therapy in a care house-results of case studies. In: ROMAN 2006-The 15th IEEE International Symposium on Robot and Human Interactive Communication. IEEE, pp 581-586

45. Schellin H, Oberley T, Patterson K, et al (2020) Man's New Best Friend? Strengthening Human-Robot Dog Bonding by Enhancing the Doglikeness of Sony's Aibo. In: 2020 Systems and Information Engineering Design Symposium (SIEDS). pp 1-6
46. Parks JA (2010) Lifting the burden of Women's care work: should robots replace the "human touch"? Hypatia 25:100-120

47. Parviainen J, Turja T, Van Aerschot L (2018) Robots and Human Touch in Care: Desirable and Non-desirable Robot Assistance. In: Ge SS, Cabibihan J-J, Salichs MA, et al (eds) Social Robotics. ICSR 2018. Lecture Notes in Computer Science. Springer International Publishing, Berlin, pp 533-540

48. Decker M (2008) Caregiving robots and ethical reflection: the perspective of interdisciplinary technology assessment. AI Soc 22:315-330. https://doi.org/10.1007/s00146-007-0151-0

49. Sparrow R, Sparrow L (2006) In the hands of machines? The future of aged care. Mind Mach 16:141-161

50. Haring KS, Mougenot C, Ono F, Watanabe K (2014) Cultural differences in perception and attitude towards robots. Int $\mathrm{J}$ Affect Eng 13:149-157. https://doi.org/10.5057/ijae.13.149

51. Cramer H, Kemper N, Amin A et al (2009) 'Give me a hug': the effects of touch and autonomy on people's responses to embodied social agents. Comput Animat Virtual Worlds 20:437-445. https://doi.org/10.1002/cav.317

52. Li S, Xu L, Yu F, Peng K (2020) Does Trait Loneliness Predict Rejection of Social Robots? The Role of Reduced Attributions of Unique Humanness (Exploring the Effect of Trait Loneliness on Anthropomorphism and Acceptance of Social Robots). In: Proceedings of the 2020 ACM/IEEE International Conference on Human-Robot Interaction. Association for Computing Machinery, New York, NY, USA, pp 271-280

53. Wolfe C (2010) What is posthumanism? University of Minnesota Press, Minneapolis

54. DeFalco A (2017) Beyond prosthetic memory: posthumanism, embodiment, and caregiving robots. Age Culture Humanities Interdiscip J 3:34

55. DeFalco A (2020) Towards a theory of posthuman care: real humans and caring robots. Body Soc 26:31-60. https://doi.org/ $10.1177 / 1357034 X 20917450$

56. van den Hoven J (2007) ICT and Value Sensitive Design. In: Goujon P, Lavelle S, Duquenoy P, et al (eds) The Information Society: Innovation, Legitimacy, Ethics and Democracy In honor of Professor Jacques Berleur s.j. Springer US, Boston, pp 67-72

57. Verbeek P-P (2006) Materializing morality: design ethics and technological mediation. Sci Technol Human Values 31:361-380

58. Nissenbaum H (2001) How computer systems embody values. Computer 34:120-119. https://doi.org/10.1109/2.910905

59. Mišeikis J, Caroni P, Duchamp P et al (2020) Lio-A personal robot assistant for human-robot interaction and care applications. IEEE Robotics Autom Lett 5:5339-5346. https://doi.org/ 10.1109/LRA.2020.3007462

60. Blond L (2019) Studying robots outside the lab: HRI as ethnography Paladyn. J Behav Robotics 10:117-127. https://doi.org/10. 1515/pjbr-2019-0007

61. Broadbent E, Tamagawa R, Patience A et al (2012) Attitudes towards health-care robots in a retirement village. Australas J Ageing 31:115-120. https://doi.org/10.1111/j.1741-6612.2011. 00551.x

62. Epstein RM, Street RL (2011) The values and value of patientcentered care. Ann Fam Med 9:100-103. https://doi.org/10.1370/ afm.1239

63. Muldoon M, King N (1995) Spirituality, health care, and bioethics. J Relig Health 34:329-350. https://doi.org/10.1007/BF022 48742

64. Seligman ME, Csikszentmihalyi M (2014) Positive psychology: an introduction. Flow and the foundations of positive psychology. Springer, Dordrecht, pp 279-298

65. Ruddick S (1980) Maternal thinking. Feminist Stud 6:342-367. https://doi.org/10.2307/3177749 
66. Gilligan C (1993) In a different voice: psychological theory and women's development. Harvard University Press, Cambridge, MA

67. Kittay EF (2019) Love's labor: essays on women, equality and dependency. Routledge, New York

68. Tronto JC (1993) Moral boundaries: a political argument for an ethic of care. Routledge, New York

69. Brinck I, Balkenius C (2020) Mutual recognition in human-robot interaction: a deflationary account. Philos Technol 33:53-70. https://doi.org/10.1007/s13347-018-0339-x

70. Sasser CG, Puchalski CM (2010) The Humanistic clinician: traversing the science and Art of Health Care. J Pain Symptom Manage 39:936-940. https://doi.org/10.1016/j.jpainsymman. 2010.03.001

71. Wu H-L, Volker DL (2012) Humanistic Nursing Theory: application to hospice and palliative care. J Adv Nurs 68:471-479. https://doi.org/10.1111/j.1365-2648.2011.05770.x

72. Paterson JG, Zderad LT (1976) Humanistic nursing. National League for Nursing New York, New York

73. Suchman LA (2007) Human-machine reconfigurations: plans and situated actions, 2nd edn, Cambridge University Press, Cambridge

74. Haraway D (2006) A cyborg manifesto: science, technology, and socialist-feminism in the late 20th century. In: Weiss J, Nolan J, Hunsinger J, Trifonas P (eds) The international handbook of virtual learning environments. Springer, Dordrecht, pp 117-158

75. DeFalco A (2020) Toward a Theory of Posthuman Care: Real Humans and Caring Robots. Body and Society (In press)

76. Fine AH (2010) Handbook on animal-assisted therapy: Theoretical foundations and guidelines for practice, 3rd edn. Academic Press, Cambridge, MA

77. Driscoll CJ (2020) Animal-assisted interventions for health and human service professionals. Nova Science Publishers, Hauppauge, NY

78. Geva N, Uzefovsky F, Levy-Tzedek S (2020) Touching the social robot PARO reduces pain perception and salivary oxytocin levels. Sci Rep 10:9814. https://doi.org/10.1038/s41598-020-66982-y

79. Sinclair S, Norris JM, McConnell SJ et al (2016) Compassion: a scoping review of the healthcare literature. BMC Palliat Care 15:6. https://doi.org/10.1186/s12904-016-0080-0

80. Wilson D (2015) CE: inside an ebola treatment unit: a Nurse's report. AJN Am J Nurs 115:28-38. https://doi.org/10.1097/01. NAJ.0000475288.30664.70

81. Turkle S (2011) Alone together: why we expect more from technology and less from each other. Basic Books, New York

82. Sharkey A (2014) Robots and human dignity: a consideration of the effects of robot care on the dignity of older people. Ethics Inf Technol 16:63-75. https://doi.org/10.1007/s10676-014-9338-5

83. Sparrow R (2002) The March of the robot dogs. Ethics Inf Technol 4:305-318. https://doi.org/10.1023/A:1021386708994

84. Meacham D, Studley M (2017) Robot Ethics 2.0 From Autonomous Cars to Artificial Intelligence. In: Lin P, Abney K, Jenkins R (eds) Could a Robot Care? It's All in the Movement. Oxford University Press, Oxford

85. Coeckelbergh M (2014) The moral standing of machines: towards a relational and non-cartesian moral hermeneutics. Philos Technol 27:61-77. https://doi.org/10.1007/s13347-013-0133-8

86. Pols J, Moser I (2009) Cold technologies versus warm care? On affective and social relations with and through care technologies. Alter 3:159-178. https://doi.org/10.1016/j.alter.2009.01.003

87. Tanaka F, Isshiki K, Takahashi F, et al (2015) Pepper learns together with children: Development of an educational application. In: 2015 IEEE-RAS 15th International Conference on Humanoid Robots (Humanoids). pp 270-275

88. TWARE (2021) Wearable tech deep touch pressure hug vest. In: Tjacket—Non-weighted hug vest that calms children, adults with anxiety, autism, ADHD, SPD, PTSD. https://www.mytja cket.com/what-is-tjacket.html. Accessed 27 Jan 2021

89. Pfadenhauer M, Dukat C (2015) Robot caregiver or robot-Supported Caregiving? Int J of Soc Robotics 7:393-406. https://doi. org/10.1007/s12369-015-0284-0

90. Reeves B, Nass CI (1996) The media equation: How people treat computers, television, and new media like real people and places. Cambridge University Press, New York

91. Martinez-Hernandez U, Prescott TJ (2016) Expressive touch: Control of robot emotional expression by touch. In: 2016 25th IEEE International Symposium on Robot and Human Interactive Communication (RO-MAN). pp 974-979

92. Engwall O, Lopes J, Åhlund A (2020) Robot interaction styles for conversation practice in second language learning. Int J Soc Robot. https://doi.org/10.1007/s12369-020-00635-y

93. Vanderborght B, Simut R, Saldien J et al (2012) Using the social robot probo as a social story telling agent for children with ASD. Interact Stud 13:348-372. https://doi.org/10.1075/is.13.3.02van

94. Coeckelbergh M (2009) Personal robots, appearance, and human good: a methodological reflection on roboethics. Int J Soc Robotics 1:217-221. https://doi.org/10.1007/s12369-009-0026-2

95. Mori M (1970) The uncanny valley. Energy 7:33-35

96. Ezer N, Fisk AD, Rogers WA (2009) Attitudinal and intentional acceptance of domestic robots by younger and older adults. In: International conference on universal access in human-computer interaction. Springer, pp 39-48

97. Kuo IH, Rabindran JM, Broadbent E, et al (2009) Age and gender factors in user acceptance of healthcare robots. In: RO-MAN 2009-The 18th IEEE International Symposium on Robot and Human Interactive Communication. pp 214-219

98. Esterwood C, Essenmacher K, Yang H, et al (2021) A MetaAnalysis of Human Personality and Robot Acceptance in Human-Robot Interaction. In: CHI Conference on Human Factorsin Computing Systems (CHI'21), May 8-13, 2021. CHI 2021

99. de Jong C, Kühne R, Peter J et al (2020) Intentional acceptance of social robots: development and validation of a self-report measure for children. Int J Hum Comput Stud 139:102426. https://doi. org/10.1016/j.ijhcs.2020.102426

100. Heerink M, Kröse B, Evers V, Wielinga B (2008) The influence of social presence on acceptance of a companion robot by older people. J Phys Agents. https://doi.org/10.14198/JoPha.2008.2.2. 05

101. De Graaf MM, Allouch SB, Klamer T (2015) Sharing a life with Harvey: exploring the acceptance of and relationship-building with a social robot. Comput Hum Behav 43:1-14. https://doi. org/10.1016/j.chb.2014.10.030

102. Hebesberger D, Koertner T, Gisinger C, Pripfl J (2017) A longterm autonomous robot at a care hospital: a mixed methods study on social acceptance and experiences of staff and older adults. Int J Soc Robotics 9:417-429. https://doi.org/10.1007/ s12369-016-0391-6

103. Sparrow R (2017) Robots, rape, and representation. Int J Soc Robotics 9:465-477. https://doi.org/10.1007/s12369-017-0413-z

104. Hirano T, Shiomi M, Iio T et al (2018) How do communication cues change impressions of human-robot touch interaction? Int J of Soc Robotics 10:21-31. https://doi.org/10.1007/ s12369-017-0425-8

105. Li JJ, Ju W, Reeves B (2017) Touching a mechanical body: tactile contact with body parts of a humanoid robot is physiologically arousing. J Hum-Robot Interact 6:118-130. https://doi.org/10. 5898/JHRI.6.3.Li

106. Fitter NT, Kuchenbecker KJ (2019) How does it feel to clap hands with a robot? Int J Soc Robot 12:113-127. https://doi.org/ 10.1007/s12369-019-00542-x

107. Fry M, MacGregor C, Ruperto K et al (2013) Nursing praxis, compassionate caring and interpersonal relations: an 
observational study. Australas Emerg Nurs J 16:37-44. https:// doi.org/10.1016/j.aenj.2013.02.003

108. Sanghavi DM (2006) What makes for a compassionate patientcaregiver relationship? Joint Comm J Quality Patient Safety 32:283-292. https://doi.org/10.1016/S1553-7250(06)32037-5

109. Majidi C (2013) Soft robotics: a perspective-current trends and prospects for the future. Soft Rob 1:5-11. https://doi.org/ 10.1089/soro.2013.0001

110. Maeda Y, Sakai T, Kamei K, Cooper EW (2020) Human-Robot Interaction Based on Facial Expression Recognition Using Deep Learning. In: 2020 Joint 11th International Conference on Soft Computing and Intelligent Systems and 21st International Symposium on Advanced Intelligent Systems (SCIS-ISIS). IEEE, pp $1-6$
111. Chesher C, Andreallo F (2020) Robotic faciality: the philosophy science and art of robot faces. Int J Soc Robotics. https://doi.org/ 10.1007/s12369-020-00623-2

112. Dalton-Brown S (2020) The ethics of medical ai and the physician-patient relationship. Camb Q Healthc Ethics 29:115-121. https://doi.org/10.1017/S0963180119000847

Publisher's Note Springer Nature remains neutral with regard to jurisdictional claims in published maps and institutional affiliations. 